\title{
Understanding Online Resource Use by Transgender Youth and Caregivers: A Qualitative Study
}

\author{
Yolanda N. Evans, ${ }^{1,2, *}$ Samantha J. Gridley, ${ }^{3}$ Julia Crouch, ${ }^{2}$ Alicia Wang, ${ }^{4}$ \\ Megan A. Moreno, ${ }^{1,2}$ Kym Ahrens, ${ }^{1,2}$ and David J. Breland ${ }^{1,2}$
}

\begin{abstract}
Purpose: This study assessed what online resources transgender youth and their caregivers use to acquire information about transgender health.

Methods: Through a variety of settings, including subspecialty clinics, support groups, and online solicitation, we recruited caregivers of transgender youth aged 22 years or younger and self-identified transgender youth aged 14-22 years. We used a mixed methods approach of conducting in-person focus groups, interviews in person or through phone, and an online survey that allowed for increased flexibility for participants and to triangulate key themes from multiple data sources. Scripts were semistructured, and prompts were focused on resources accessed by transgender youth and their caregivers.

Results: We had a total of 65 participants, including 50 caregivers and 15 youth. Five main themes emerged from participants on why they sought out information on the Internet and what they found in their online searches. These themes include (1) exploring gender identity, (2) filling knowledge gaps, (3) seeking support networks, (4) finding transgender-friendly providers, and (5) encountering misinformation.

Conclusion: Our findings demonstrate the need for reliable trustworthy content online, the importance of the virtual community to support both youth and caregivers, and the challenge of navigating misinformation that is often faced by transgender youth as they navigate online resources. We propose partnering with professional organizations, such as the American Academy of Pediatrics or World Professional Association of Transgender Health, to promote evidence-based guidelines, position statements, and online information on healthcare for transgender youth.
\end{abstract}

Keywords: adolescents; health information; Internet; online resource; social network; transgender

\section{Introduction}

Transgender youth and parents of transgender youth seek information to guide their medical decision-making and inform their choices for health-related care. ${ }^{1}$ Sources of health information and emotional support for patients can come in many forms. Pediatric institutions where transgender youth receive multidisciplinary healthcare have the potential to serve as places of expertise and support for local patients and their families, ${ }^{2}$ as well as for individuals within the broader national and even inter- national transgender community. Although a number of multidisciplinary gender clinics exist around the United States, they are largely concentrated in urban areas. ${ }^{3}$ Many transgender youth face barriers to healthcare, including a lack of medical specialists comfortable in managing their specific health needs; inconsistently applied protocols for management of gender-affirming treatments; and difficulty advocating for themselves in the medical setting, such as asking that their preferred name and pronouns be used. ${ }^{1}$

\footnotetext{
${ }^{1}$ Department of Pediatrics, University of Washington, Seattle, Washington.

${ }^{2}$ Seattle Children's Research Institute, Seattle, Washington.

${ }^{3}$ Vanderbilt University School of Medicine, Nashville, Tennessee.

${ }^{4}$ University of Washington School of Medicine, Seattle, Washington.
}

*Address correspondence to: Yolanda N. Evans, MD MPH, Department of Pediatrics, University of Washington, 4540 Sand Point Way NE, Suite 200, Seattle, WA 98105, E-mail: yolanda.evans@seattlechildrens.org

(c) Yolanda N. Evans et al. 2017; Published by Mary Ann Liebert, Inc. This is an Open Access article distributed under the terms of the Creative Commons Attribution License, which permits unrestricted use, distribution, and reproduction in any medium, provided the original work is properly cited. 
More than 74\% of American homes have Internet access, ${ }^{4}$ and online sources of health information are becoming a regular part of patient care. ${ }^{5}$ Given its widespread availability across U.S. households, the Internet has the potential to be leveraged as an important tool to help tackle the barriers that currently inhibit transgender youth from obtaining accurate genderrelated health information and evidence-based genderaffirming healthcare. Indeed, adolescents and their caregivers are already turning to the Internet for knowledge acquisition regarding a broad spectrum of health issues. ${ }^{6,7}$ Online resources can disseminate information about available therapies, supplement knowledge gained through medical providers, and provide a supportive environment for exploration of emotions with online communities of people who share similar experiences. ${ }^{8}$ The use of the Internet to form and foster social connection among transgender adults, as well as to disseminate information and organize transgender activist work, is well documented. ${ }^{9,10}$ Blogs in particular are frequent sources of support and information for patients with chronic health conditions and their parents. ${ }^{7,11,12}$

Internet use in transgender and gender nonconforming persons has been explored. McInroy and Craig investigated 19 LGBTQ young adults' perceptions of portrayals of LGBTQ people in online and offline media. ${ }^{8}$ Their findings highlighted the utility of online resources to connect transgender youth to a supportive community as well as to convey the real-life experiences of transgender persons through social media and YouTube videos. However, a limitation of this study was that only four transgender young adults' perspectives were captured. No study to date has explored this topic from the perspectives of teens and young adults who identify as transgender or gender nonconforming. Moreover, the use of online resources among those seeking information about transgender health may differ from the passive consumption of media by LGBT youth, as was examined in the aforementioned study.

Little is known about what online resources transgender youth and their caregivers may be using to augment their knowledge and answer their questions about transgender health. Even less is known about what specific information this population is actively seeking through online resources. This study aims to assess the questions transgender youth and their caregivers have about transgender health and what online resources they are currently utilizing to acquire information on this topic. This study also aims to identify potential deficits or inconsistencies that exist in the resources they are finding. Of note, this study was part of a larger research project on barriers to accessing gender-affirming healthcare for transgender youth. Results from the larger study have been published previously. ${ }^{1}$

\section{Methods}

We recruited two participant groups for this study. One group consisted of parents, foster parents, and other legal guardians who are parenting transgender youth aged 22 years or younger. We will refer to this group as caregivers for the remainder of this article. The second group recruited consisted of self-identified transgender youth aged 14 to 22 years. For this study, transgender was defined as having a gender identity that differed from the sex assigned at birth. Youth participants endorsed a range of gender identities, including transgender male, transgender female, or a gender identity outside the male/female gender binary. Participants were recruited through multiple avenues, including in-person recruitment during clinical encounters at an Adolescent Medicine subspecialty clinic, flyers at Seattle-based organizations supporting transgender youth, and online solicitation through Teenology101, a blog sponsored by Seattle Children's Hospital and written by an Adolescent Medicine attending physician (Y.N.E.). Although the online survey was available to caregivers of transgender youth nationwide, the majority of our recruitment efforts were concentrated in Washington State. Due to the variety of recruitment strategies used, including online postings, we were unable to determine the number of potential participants who declined participation in the study.

We used a mixed methods approach, including inperson focus groups lasting $2 \mathrm{~h}$, interviews either in person or through phone lasting 20-40 min, and an online survey available through the Teenology101 blog (Fig. 1). This approach allowed us to increase flexibility for participants and triangulate key themes from multiple data sources. Interview and focus group scripts were semistructured. Prompts were focused on types of resources previously accessed by participants when seeking information about transgender health, the quality and accuracy of those resources as perceived by participants, and barriers to gender-affirming healthcare faced by transgender youth and their caregivers. The survey contained free response and multiple-choice components. All recruitment and data collection occurred in 2015.

All interviews and focus groups were audio-recorded and transcribed. A preliminary code book of proposed 


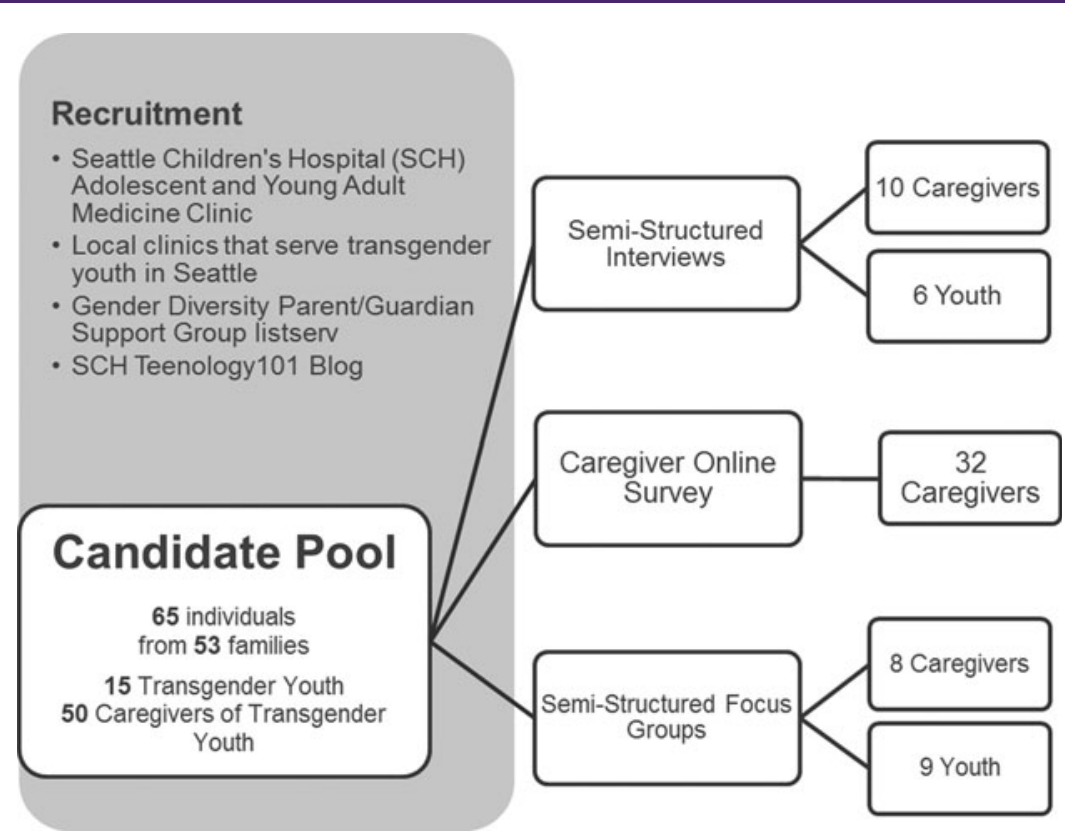

FIG. 1. Study recruitment and participants. Reproduced with permission from Ref. ${ }^{1}$

themes for the analysis of data was developed using clinical experience. This code book was adapted, and an inductive approach was used to identify new codes based on additional themes that arose during data collection. Analysis began while data were still being collected; however, recruitment closed once thematic saturation was reached. We used Atlas.ti software to conduct the thematic analysis of the qualitative data. ${ }^{13}$ This process consisted of identifying themes about online access to information that emerged throughout the participants' discussions of their healthcare experiences, applying codes to participants' transcribed quotes, and assessing frequency of recurring themes across the data set.

This study was approved by the Seattle Children's Hospital Institutional Review Board. Written caregiver and youth consent/assent, as applicable by age, was obtained in advance of focus group or interview participation. Documentation of written consent was waived for survey participants, who instead viewed the consent form information on the survey website and clicked "I agree" before proceeding with survey participation.

\section{Results}

This study had a total of 65 participants, including 50 caregivers and 15 youth. Three quarters of our participants were Washington State residents, and the majority of participants were white. Caregiver participants were predom- inantly female, and more than two-thirds of caregivers had obtained a bachelor's degree or higher (Table 1).

Both caregivers and youth described having accessed a variety of online resources to acquire information about transgender health, including blogs, websites, search engines, and listservs (Table 2). From participants' discussions of why they turned to the Internet for transgender health information and what they encountered through their search, five main themes emerged: (1) exploring gender identity, (2) filling knowledge gaps, (3) seeking support networks, (4) finding transgender-friendly providers, and (5) encountering misinformation. In this section, we will describe these themes using illustrative quotes (Table 3).

\section{Exploring gender identity}

A commonly experienced struggle discussed by youth and caregiver participants was the lack of vocabulary to adequately describe their or their child's sense of self when they first sensed that they were different from those around them. Unequipped with the language to define precisely this difference that they were seeking information about, most participants turned to online sources-as opposed to hard copy resources or their healthcare provider-with their initial inquiries about what this sensation might mean and whether other people existed who felt similarly different. 
Table 1. Demographics of Study Participants

\begin{tabular}{|c|c|c|}
\hline & Caregiver participants, $n=50$ & Youth participants, $n=15$ \\
\hline Age, average (range) & 47 (29-71 years) & 18 (14-22 years) \\
\hline Gender identity, $n(\%)^{\mathrm{a}}$ & $\begin{array}{l}\text { Female: } 40(83) \\
\text { Male: } 7 \text { (15) } \\
\text { Trans-masculine: } 1(2) \\
\text { Did not answer: } 2\end{array}$ & $\begin{array}{l}\text { Trans-feminine: } 3(20) \\
\text { Trans-masculine: } 7(47) \\
\text { Other }^{\text {b. }} 5(33)\end{array}$ \\
\hline Sex assigned at birth, $n(\%)$ & [Data not collected] & $\begin{array}{l}\text { Female: } 10(67) \\
\text { Male: } 5(33)\end{array}$ \\
\hline Race/ethnicity, $n$ (\%) & $\begin{array}{l}\text { White: } 39 \text { (78) } \\
\text { Black/African American: } 2 \text { (4) } \\
\text { Native American/American Indian } \\
\quad \text { or Alaska Native: } 2 \text { (4) } \\
\text { Hispanic/Latino(a): } 1 \text { (2) } \\
\text { Asian/Pacific Islander: } 2 \text { (4) } \\
\text { More than one race/ethnicity: } 4 \text { (8) }\end{array}$ & $\begin{array}{l}\text { White: } 10(67) \\
\text { Black/African American: } 0(0) \\
\text { Native American/American Indian } \\
\quad \text { or Alaska Native: } 1(7) \\
\text { Hispanic/Latino(a): } 1 \text { (7) } \\
\text { Asian/Pacific Islander: } 0(0) \\
\text { More than one race/ethnicity: } 3 \text { (20) }\end{array}$ \\
\hline Education, $n$ (\%) & $\begin{array}{l}\text { Advanced degree: } 14 \text { (29) } \\
\text { Bachelor's degree: } 19 \text { (39) } \\
\text { Some college/vocational school: } 13 \text { (27) } \\
\text { High school diploma/GED: } 3 \text { (6) } \\
\text { Did not answer: } 1\end{array}$ & $\begin{array}{l}\text { Some college/vocational } \\
\text { school: } 4(27) \\
\text { High school diploma/GED: } 5(33) \\
\text { Currently in high School: } 6(40)\end{array}$ \\
\hline Marital status, $n(\%)$ & $\begin{array}{l}\text { Married: } 35(71) \\
\text { Divorced: } 8(16) \\
\text { Separated: } 1(2) \\
\text { Single: } 4 \text { (8) } \\
\text { Domestic partnership: } 1 \text { (2) } \\
\text { Did not answer: } 1\end{array}$ & [Not applicable] \\
\hline State of residency, $n$ (\%) & $\begin{array}{l}\text { WA: } 33(67) \\
\text { Other state (not WA) }{ }^{c}: 16(33) \\
\text { Did not answer: } 1\end{array}$ & $\begin{array}{l}\text { WA: } 15(100) \\
\text { Other state }\end{array}$ \\
\hline $\begin{array}{l}\text { Age at which realized gender identity } \\
\text { was different from sex assigned at birth, } n(\%)\end{array}$ & [Not applicable] & $\begin{array}{l}\text { Age }<7: 2(18) \\
\text { Age } 8-13: 6(55) \\
\text { Age 14-17: } 3(27) \\
\text { Age } \geq 18: 1(9) \\
\text { Did not answer: } 3\end{array}$ \\
\hline Pubertal blockers, $n$ (\%) & & $\begin{array}{l}\text { Received: } 2 \text { (20) } \\
\text { Want or might want: } 0(0) \\
\text { Did not want (was eligible): } 0 \text { (0) } \\
\text { Too old for blockers (was not eligible): } 8 \text { (80) } \\
\text { Did not answer: } 4\end{array}$ \\
\hline Cross-sex hormones, $n(\%)$ & & $\begin{array}{l}\text { Received: } 9 \text { (64) } \\
\text { Want or might want: } 4 \text { (28) } \\
\text { Do not want: } 1 \text { (7) } \\
\text { Did not answer: } 1\end{array}$ \\
\hline Gender-affirming surgery, $n(\%)$ & & $\begin{array}{l}\text { Received: } 0(0) \\
\text { Want or might want: } 7(100) \\
\text { Do not want: } 0(0) \\
\text { Did not answer: } 8\end{array}$ \\
\hline
\end{tabular}

Reproduced from Ref. ${ }^{1}$

aPercentages for some variables do not add up to 100 due to rounding.

"'Other" gender identities included genderqueer, gender fluid, nonbinary, trans-masculine/genderqueer, and androgenous.

'Participants' states of residency outside of WA (one each): AZ, CA, CO, GA, FL, MD, NC, OR, PA, TN, and TX.

"I started by searching on the Internet."-Caregiver

“...I did a lot of reading online.”-Caregiver

"I've looked on the Internet, because that's where everybody looks."-Youth, age 18

Some caregivers recalled their child explaining to them that Internet research provided answers to questions about their child's identity before their child had even been able to articulate those questions. These answers not only generated new questions and complex emotions for both caregiver and youth participants but also provided the benefit of direction for further exploration.

"[Our son] told us that he had been doing a lot of research online ... He'd known that something was different about himself for a really, really long time, but wasn't sure exactly what it 
Table 2. Online Resources About Transgender Health That Were Accessed by Study Participants

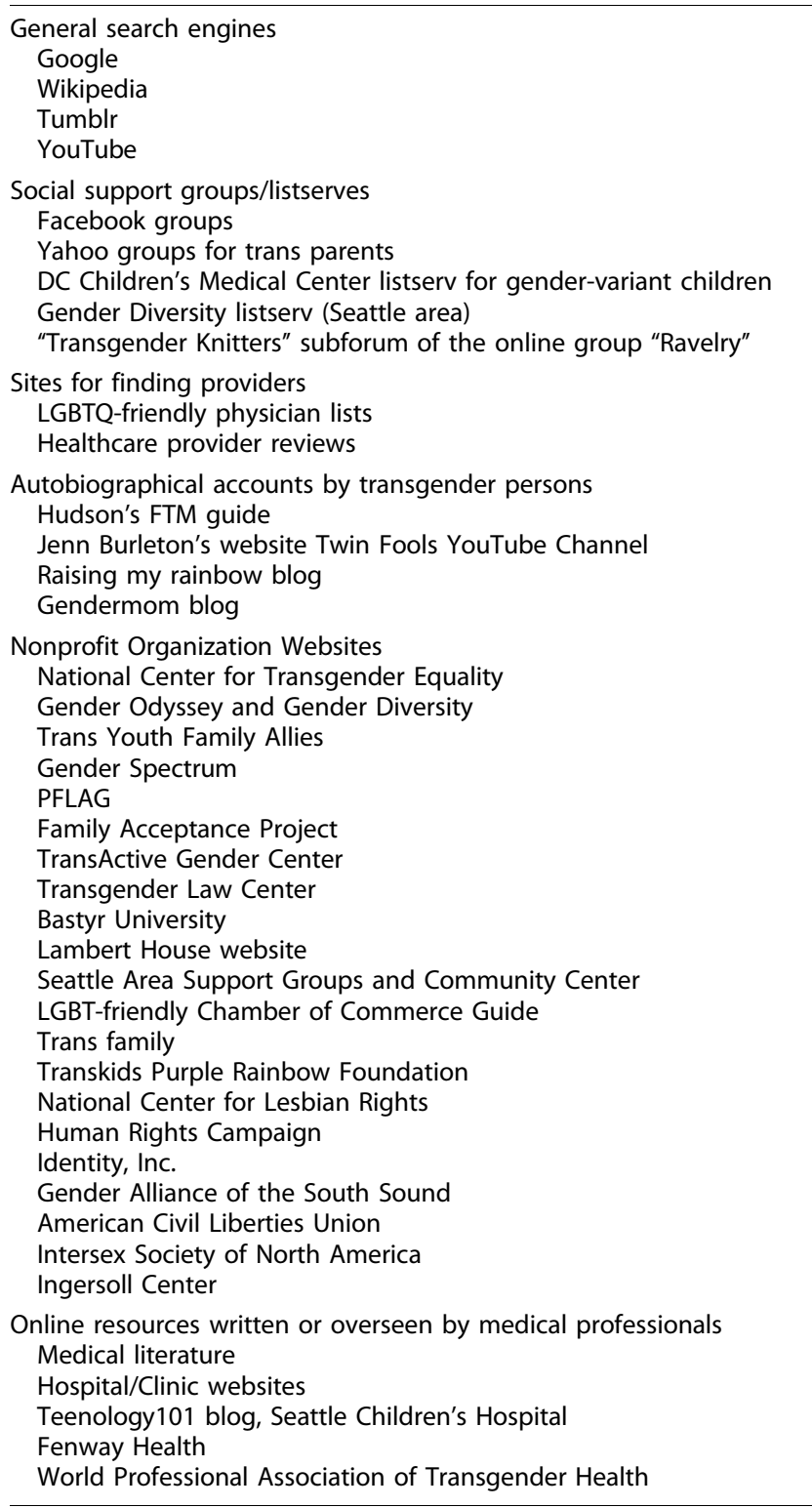

was, and then after doing some research, discovered that he was actually a male in a female body, and so he was really nervous and really scared, and of course we were [too]...but thankfully, even though this was not something that we [had] dealt with before [at least we had information]."-Caregiver

For many participants, the Internet search for the vocabulary to describe what they or their child was experiencing did not immediately produce a term that was accurate. Many youth participants described a process of adopting and discarding different labels before they were able to finally land on a gender identifier that they felt accurately matched their true gender identity, for example, gender fluid, transgender male, and nonbinary. Some youth initially (mis)attributed their gender dysphoria to a nonheterosexual orientation before adopting a gender identity label that (more) accurately described their internal sense of self. However, at least one youth participant in the study did identify as both transgender and nonheterosexual. Most caregivers in our study reported supporting their child as they tried on various identifiers that they had discovered or researched online.

"He just wasn't sure what the terminology was as to how he was feeling until [he] started watching all these YouTube things, and [thought] 'That's how I feel. Maybe this is what I am.' So we went through the bisexual. We went through the gay. We went through lesbian, all that kind of stuff. Then we got to gender neutral...then when it came to transgender, [my child said] 'I think that's what it is. I think that's what fits." -Caregiver

For a few youth, exposure to online content about gender variance deconstructed their previously held negative beliefs about transgender persons. For example, one youth noted that reading online about a spectrum of gender identities empowered him to face questions he had been subconsciously repressing about his own gender identity.

"I actually heard [about transgender identities] on Tumblr, because that was what got me all my information on all the gender-variant stuff. I used to think I was straight and

Table 3. Key Themes

\begin{tabular}{|c|c|}
\hline Theme & Example quote \\
\hline Exploring identity & "I've looked on the Internet, because that's where everybody looks."-Youth \\
\hline Filling knowledge gaps & $\begin{array}{l}\text { "I immediately was just Googling to try and figure out what to do, 'cause I was like we needed medical } \\
\text { therapy, you know everything."-Caregiver }\end{array}$ \\
\hline Seeking support networks & $\begin{array}{l}\text { "Most of the friends that helped me with this discovery and stuff don't live anywhere near me. There's a lot } \\
\text { of straight-cis people here and not very many trans people at all. So I had to find people through online, and } \\
\text { conventions, and stuff."-Youth }\end{array}$ \\
\hline $\begin{array}{l}\text { Finding providers supportive } \\
\text { of transgender persons }\end{array}$ & $\begin{array}{l}\text { "I mostly searched online trying to find LGBTQ-friendly physicians, and I don't recall the websites off the top } \\
\text { of my head, but there's an organization that physicians can belong to that identify them as LGBTQ- } \\
\text { friendly..."-Caregiver }\end{array}$ \\
\hline Encountering misinformation & $\begin{array}{l}\text { "Tumblr, that's a bad site... That's a bad site to get your medical information from... People spread } \\
\text { misinformation like it's going out of fashion."-Youth }\end{array}$ \\
\hline
\end{tabular}


cisgender. I actually used to be transphobic and really rude. And I found out more and more because there are some very, very informative blogs that I would go on and read about. I actually was very relieved to find out these things and that what I was feeling [were] really normal." - Youth, age 17

Youth often found that sources online not only affirmed their feelings as legitimate but also reassured them that people can undergo a successful social transition of their gender, as well as hormonal or surgical transition if that is desired.

\begin{abstract}
"[My girlfriend told me], 'Well there's this cosplayer, and he's trans...he has all these transition videos,' and that's how I [realized] 'Oh, there's a word for how I'm feeling and there's people like me and I'm not just ridiculous.' It was kind of like 'Oh, this is a real thing that people actually can do: transition."'-Youth, age 17
\end{abstract}

\section{Filling knowledge gaps}

As caregivers and youth found the terminologies that fit their gender identity, their Internet searches shifted toward seeking information on what to do next. This included searches for how to proceed with finding gender-related healthcare and what options were available for transitioning physically to align their body to their identified gender. Many caregiver participants reported first attempting to access transgender healthcare information for their child while having minimal to no prior knowledge of the topic themselves.

\footnotetext{
"I immediately was just Googling to try and figure out what to do, 'cause I was like we needed medical therapy, you know everything."-Caregiver

"I've searched for information online, as well as with my health providers...So I've been looking and searching for health services that could benefit me in my search for being able to become what I really want to be..."-Youth, age 17
}

Interestingly, youth participants often cited online articles and blogs written by laypersons, rather than healthcare professionals, as their preferred platform for acquiring information about medically transitioning. In response to asking which websites were most useful, one youth participant responded:

"Wikipedia, Google, like anything that has to do with trans medical information... for medical stuff, I think Wikipedia and I think some hospitals have a page for that kind of stuff."

Online content written by nonmedical professionals was noted to be helpful not only for information about medically transitioning-including pubertal blockers, hormone treatments, and surgical options-but also for advice and tips about methods to affirm one's identified gender through reversible methods that assist with a social transition, such as binding, tucking, or packing.
"...I know for [my son] online has been a huge help for him to look for information, especially, 'where [do] you get a binder?' you know. 'How do you [transition]?"'-Caregiver

Some youth participants noted that they had perused various online autobiographical narratives about transitioning to understand the possible paths for their own social and medical transition. These websites, although not medically fact-checked, were often cited as youth participants' preferred online resource because of their easy-to-understand conversational language and first-person narration, as opposed to the impersonal jargon the youth encountered-or expected to encounter-on hospital websites.

\begin{abstract}
"I guess the most helpful things were blogs and stuff, because looking on the hospital websites, I didn't really understand I guess a lot of the what they had to offer in terms of getting set up with the doctor and getting set up for hormone therapy and everything, 'cause everything was just kind of talked about... there were more ideas than programs that were actually like readily available to be signed up for.... So I guess blogs were the best thing, because I could see what people had actually done and what was working for people and could kind of read through some experiences and kind of base my further research off of that and [understand] where I should move forth and stuff."-Youth, age 19
\end{abstract}

\section{Seeking support networks}

Participants described developing close friendships through online support networks for transgender youth or caregivers of transgender youth. These social media networks were especially valued by participants who did not live in the vicinity of any other out transgender person or in settings in which there existed few or no offline transgender health resources. These online friendships, which frequently spanned large geographical distances, were viewed by some of the youth as their only option for finding individuals with similar experiences.

\footnotetext{
"Most of the friends that helped me with this discovery and stuff don't live anywhere near me. There's a lot of straightcis people here and not very many trans people at all. So I had to find people through online, and conventions, and stuff."-Youth, age 17
}

Online social connections enabled youth to learn more about others' lived experience at different points along a gender identity spectrum, which allowed them to contextualize or normalize their own experience. For those youth who were not yet out with their transgender identity, these support groups provided highly desired practical knowledge about what to expect if they were to socially transition to their identified gender, such as by wearing clothes in the style of that gender or asking others to call them by a different name 
than their name assigned at birth. For those who had socially transitioned, online friendships with other transgender persons often provided affirmation and support amid bullying and ostracism by some family members and previous friends.

"I eventually made friends with trans people and they told me more [about being transgender]. I'm still honestly really questioning-not my gender identity, but more my [sexual] orientation and stuff because I'm still finding out more and more about [living as a] trans[gender person] and stuff, through friends, and blogs, and stuff."-Youth, age 17

Similarly, caregiver participants often turned to online social support groups and group forums for parents of transgender youth because they lacked easily accessible offline resources about transgender health. These social networks served not only as a resource for information gathering and sharing but also as a safe space for caregivers who wanted to support their child, but were struggling to navigate unfamiliar territory.

“[A children's hospital] in Washington, D.C. had a parent listserv group that I joined, and there was a Gender Clinic there... delving more into what to do with these gendervariant kids who are expressing at such a young age. And so...I was able to form some connections online, just at least I could email and ask some questions and to-in the group setting, and we could get answers."-Caregiver

Caregivers reported a feeling of camaraderie within the online network of families. This was especially valuable for caregivers who lived far from other caregivers of transgender youth or who were otherwise isolated and grappling with these changes alone.

"Having just this, the email group.... and knowing that they're out there [benefitted me]. Even if they're not local, they're out there. [My child] has... a forum online so that the parents can connect with each other and get information. So we figured out what the next steps were [for transitioning], even though there was a huge learning curve."-Caregiver

One youth participant not only gleaned information about medically transitioning from online social networking but also added his own transition experience to the pool of online autobiographical transgender narratives. While discussing his video blog, he described the elation he experienced when reviewing his own videos in sequence and noting the physical changes he had undergone after he began taking testosterone.

"I was so excited. The first time that I realized that my voice had gotten deeper, I did not want to stop talking about it. Just to hear my own voice. And I've been doing a blog since I've started [taking testosterone], so I can actually see and hear the changes between a video last week, to a video five months ago before I started [testosterone]."-Youth, age 17
The blog allowed this participant to not only chronicle his own gender journey but also to experience supportive social connectivity while transitioning. He proudly noted, "I think I just hit like 200 followers on Tumblr with [the video blog]."

\section{Finding providers supportive of transgender persons}

Many participants reported difficulty finding a healthcare provider who was adequately trained in transgender healthcare and felt confident administering genderaffirming treatments such as cross-sex hormones and pubertal blockers. Faced with gender dysphoria that was increasingly amplifying as their or their child's puberty progressed, most youth and caregiver participants turned to the Internet to seek competent healthcare providers who could facilitate their transition.

Participants did not uniformly pinpoint any one particular resource as most valuable for helping them find knowledgeable and affirming medical and mental healthcare providers in their geographic region. Rather, participants collectively described a vast variety of sources as moderately helpful for this purpose, including blogs, Internet searches, hospital websites, and social networks. Caregivers began their search for LGBT-affirming pediatric providers predominantly through a combination of online searches, perusing their insurance carrier's list of in-network providers, and checking out local healthcare and mental health organizations. Caregivers found it particularly helpful when they found specific mention of transgender-friendly clinicians on providers' websites and in their offices, such as a sign on the registration desk indicating that they welcome patients and families of all sexual orientations and gender identities.

"I mostly searched online trying to find LGBTQ-friendly physicians, and I don't recall the websites off the top of my head, but there's an organization that physicians can belong to that identify them as LGBTQ-friendly..."-Caregiver

Although the Internet was a common starting place for caregivers looking for a physician for their transgender child, a few caregivers realized they were uncomfortable scheduling an appointment with a provider they found online whom they did not know or trust. In those cases, caregivers returned to offline resources they knew and respected.

\footnotetext{
"I mean I did do research on the Internet, and there's tons of websites on [transgender health care], but none of them give credentials of the different people that I came across, and it's just like 'Yeah, I'm not comfortable jumping into that boat yet, not knowing where we're starting.' So that's where I started, with our General Pediatrician first."-Caregiver
} 
Mental health providers who are specifically supportive of and experienced working with transgender persons proved to be challenging to find. Insurance network limitations further narrowed the pool of therapists, psychologists, and psychiatrists who fit this description.

"I couldn't find a counselor that counseled children with gender issues. They all wanted to counsel me... Finding a therapist who has experience with LGBT and adolescent issues was seemingly impossible."-Caregiver

For some caregivers, their own online browsing or search assistance from guidance counselors at school yielded useful results.

"[I did a] big Internet search... through the school psychologists, [I] have been given lists of psychologists to kind of look through, and then using the Internet to go on websites and research them [before I] make all the phone calls. So that's been helpful."-Caregiver

Some youth took on the responsibility of finding their own healthcare providers that best fit their gender-related healthcare needs. Similar to caregivers, youth used a combination of Internet resources such as Google searches and blogs to find medical providers.

"[My resources have] mostly been Internet stuff. I found the doctor that I'm going to for my hormone therapy through a friend who also sees him for hormone therapy. So, I guess friends [have been a resource] too, but it's mostly been online research."-Youth, age 17

Some participants described realizing that although healthcare providers may advertise themselves as being transgender-friendly, there is no regulation on how accurately this reflects a clinician's knowledge and experience in working with transgender patients. A few participants expressed frustration that this label can be applied at the provider's discretion. Youth who used Internet resources were aware of this potential discrepancy between stated competency with transgender youth and actual knowledge base or comfort level, yet the youth often were left with no other choice than to trust their Internet search.

\footnotetext{
"...but to find the Provider I see now, I used the Psychology Today website and looked up people who had checked [the box] that they were trans-competent, and [my provider] seems to be so far, which is some sort of miracle, because usually when people say that, they actually aren't."-Youth, 19
}

Just as participants described online support groups as helpful avenues by which youth could explore and affirm their gender identity, Internet forums were also cited as a space to share information about healthcare professionals.

"I'm a member of a Facebook group... and they actually have like a pretty impressive list running of doctors in specific spe- cialties that they've seen who were good, and doctors in specific specialties who you should absolutely not go to, because they're not trans-friendly." - Youth, age 19

\section{Encountering misinformation}

Online sources of transgender health information that were accessed varied widely among participants and no single resource was universally cited as being the most reliable, accurate, or trusted. Caregivers and youth encountered blatant misinformation, unfiltered extreme opinion pieces (such as conversion sites), malicious Internet postings littered with hate speech, and websites full of advertising that diminished trust in the Internet source. While many youth participants used broad Internet searches, including sources such as Wikipedia and Google ("Just some starting out on Google and going from there"), a few felt that the Internet was too unfiltered and unregulated to provide accurate or complete information.

\footnotetext{
"Tumblr, that's a bad site... That's a bad site to get your medical information from... People spread misinformation like it's going out of fashion."-Youth, age 18

"It's very scary, and the absence of information, even on the Internet where... we're so accustomed to finding what we need to know, and [transgender health information] was not there, and I know now there's a lot more and you can type in different search terms and come up with a lot more now, but back then [when I was searching for transgender health information for my child ten years ago] there was really very, very little."-Caregiver
}

Many caregiver participants in the survey discussed Internet research as being risky. For example, a few caregivers doing their own online browsing became quickly aware that some websites masquerading as fact-based resources actually advertised unrelated treatments and surgeries in an attempt to profit from a potentially vulnerable population.

\footnotetext{
"...what you do find on the Internet is really limited, or the people who pay to be up on the Internet or have the resources to put themselves out there and advertise. A lot of the surgery, plastic surgery [I read about online] was cosmetic surgery that wasn't necessarily geared to transgender youth, or youth at all." -Caregiver
}

Similarly, caregivers reported being troubled by antitransgender messaging within online resources that they accessed.

"[My] a teenage child [was] searching the Internet for information, as much as he might've found help, he also found a lot of things that were very disturbing, very troubling, like 'Transgender people are not real people,' and oh the gamut, the gamut of anything you can imagine [such as] that 'they're not human' or 'they're not worth anything,' ... oh my favorite, 'How can they know at this age? How can they know what their gender identity is?' ...there's a lot of negative stuff out there. You have to be very careful." - Caregiver 
Caregivers were disappointed to find that malicious messaging was often hidden behind what initially appeared to be helpful information.

\footnotetext{
"Some very scary conversion-type websites came up, and some even start off by seeming at least in the search engine you think you maybe found something, and you dig a little deeper and it's religiously-affiliated, or it's reparative therapy-type conversation therapy."-Caregiver
}

Youth participants expressed similar experiences with finding misinformation online.

"So there was a lot of... essentially looking to the Internet and looking in the library for a lot of resources, and what's sad about it was a lot of them were pretty outdated and a lot of the language was very kind of early ' 90 s, late ' 80 s and I was like 'What is this?'”-Youth, age 17

\section{Discussion}

The results emphasized that this unique population of patients and caregivers used Internet resources in a variety of ways. As with other individuals who have unique healthcare needs, ${ }^{14,15}$ transgender youth and caregivers search for knowledge and information about transgender health, gender terms, and gender-affirming care. Online searches are used both to explore terminology and identify others who may be undergoing a similar experience. Many described the Internet as the first place they explored when they or their child began identifying as have a gender identity that differed from their sex assigned at birth. The Internet is a source of social support, with online networks playing a substantial role in providing a sense of community for both transgender youth and their caregivers. Online community and social support has strong potential to serve as a resource for transgender youth who may not have access to resources. Future research should explore online social networks as a possible intervention that could decrease negative health outcomes for transgender youth. Despite these positive associations with online resources, there are also concerns.

Participants cited the abundant misinformation that was found using Internet searches. For adolescents who are exploring their gender identity, encountering conversion websites or biased information may lead to emotional distress, lack of validation for their feelings, and significant harm in a population already at risk for anxiety, depression, and suicide. ${ }^{16}$ Notably, conversion therapy has been condemned by many professional medical associations, including the American Academy of Pediatrics, ${ }^{17}$ the American Medical Association, ${ }^{18}$ the American Academy of Child and Adolescent Psychiatry, ${ }^{19}$ and the American College of Physicians. ${ }^{20}$ It is therefore alarming that websites promoting this practice arose frequently in participants' web-based searches for knowledge about gender identity and transgender health. For caregivers, misinformation may lead to denied validation of their youth's identity or frustration when trying to find information to further their youth's development. In addition to the presence of misinformation about transgender health and identities online, the recently publicized censorship of LGBT-related videos under YouTube's Restricted Mode raises additional concern. This YouTube filter, which offers settings to hide explicit content, may be prohibiting some transgender youth and their caregivers from accessing nonexplicit LGBT-affirming content online, which could increase the likelihood that the LGBT-related content they do encounter is not affirming of their or their child's identity. ${ }^{21}$

Participants noted the lack of any ability to verify credentials for healthcare professionals online when searching for gender-affirming care. Both youth and caregivers reported trusting individual layperson stories and recommendations when seeking transgenderfriendly healthcare providers over information provided on websites associated with health institutions.

To remedy these concerns, healthcare providers can act in a variety of ways. First, leaders in transgender health can work together to create up-to-date, accurate online content. Our results suggest that content presented in the form of written blogs, video blogs, or social media sites may appeal to transgender youth as youth participants in our study frequently cited viewing online transgender health sources in these formats published by laypersons. Providers can partner with patients and their community to create advisory boards-which would help in keeping institutional online content engaging and current-or partner with private vendors to create and market content. However, creating content as an individual provider is not scalable to reach a large audience.

To have a more widespread network of information, professional societies engaged in the medical care of adolescents (including the disciplines of Pediatrics, Endocrinology, Family Medicine, Obstetrics and Gynecology, Psychiatry, and subspecialty of Adolescent Medicine) can continue to offer and regularly update resources and position statements regarding gender-affirming healthcare. They may offer online forums or distribution lists that allow patients and families to develop a community within the professional network. They can also partner with organizations such as the World Professional Association for Transgender Health to create social support communities for transgender 
youth and their caregivers; these communities can serve as novel platforms for distributing and updating transgender health information. A certification or credentialing process in transgender health has potential to certify expertise; however, the disadvantages include, but are not limited to, defining who would oversee the credentialing process, what fees would occur, which providers would be eligible, and who would define the terms of being credentialed. Transgender health competencies could be included in training programs of disciplines that routinely care for transgender youth and adults. As an example, some medical schools, including the Vanderbilt University School of Medicine, ${ }^{22}$ offer LGBT Health Certificate Programs for medical students with interest in providing identity-affirming healthcare for LGBT patients. This type of training could be expanded in Adolescent Medicine and Pediatric Endocrinology fellowship programs for providers to have access to formal medical training in transgender health.

Finally, even in the absence of creating accurate online transgender health content themselves, healthcare providers should educate youth and caregivers on how to be good consumers of Internet content. This includes teaching the aspects of a website that signify whether the information presented is accurate, reliable, and trustworthy. Nearly half of all transgender-related websites are operated by individuals or groups not affiliated with a recognizable organization, and $17 \%$ are operated by for-profit businesses; therefore, it is important for users to understand potential motives behind the content they are reading. ${ }^{23}$ Education on how to identify untrustworthy websites (such as looking for author credentials or the organization that sponsored the content) should lead users to be appropriately skeptical or accepting of the validity of what they read online.

This study had several limitations worth noting. The sample size was small, and youth participants were underrepresented compared with caregiver participants (50 caregivers vs. 15 youth). Most participants were residents of the same geographic location (Washington State). Due to the variety of modalities used to recruit participants, information for this study was obtained in different ways (in-person interviews, focus groups, and online survey). Participants may have provided different responses due to the nature of how they participated. For example, participants completing an online survey may have been more straightforward with responses than someone being interviewed in person. The population studied was also highly educated with a very limited number of participants coming from underrepresented ethnic and socioeconomic backgrounds. Due to this selection bias, the results cannot be generalizable to all caregivers or all transgender youth. Another limitation is that the participants did not identify the year in which their online searches occurred. Content found in online searches 10 years ago will be very different from more recent searches for information on transgender health. We assume that searches occurred within the past 5-10 years based on the age of youth participants and caregivers' transgender children, but this cannot be verified. Additionally, caregiver participants were overall very supportive of their youth and many youth participants expressed feeling supported by at least one member of their family. These characteristics of our participant pool are likely a product of parental consent being required for youth participation. Supportive caregivers are more likely to seek out and volunteer to participate in studies related to transgender youth, and youth under age 18 would be unable to participate without the support and consent of at least one legal guardian.

Despite these study limitations, the results yield important considerations. As transgender youth and their caregivers seek and obtain information from peers, community networks, and known healthcare providers, online resources are also frequently utilized to access health-related information. Online forums serve as a means of remaining connected, finding information, and sharing content. For healthcare providers, acknowledging the importance of the Internet in the journey of gender identity has implications for health behaviors and development that should not be ignored. The Internet is a tool that can be used not only to provide information but also to create a sense of community, provide social support, and aid families in finding a supportive gender-affirming healthcare team. More research is needed on how to eliminate barriers transgender youth face in receiving health information and care as well as on how the Internet can be a resource in decreasing those barriers. Additionally, further research is needed on how caregivers who oppose their child's gender identity search for and consume information online and offline about transgender health and identities.

\section{Acknowledgments}

The authors gratefully acknowledge the study participants for sharing their experiences. They thank Aiden Key for his support in creation of the original study 
and participant recruitment. The authors appreciate the assistance of Dr. Hatfield, Dr. Gromko, Lambert House, Seattle Counseling Services, and Seattle Children's Hospital Marketing and Communications in the distribution of recruitment materials. The authors thank RaNette Schaff, Emily Antoon, Whitney Eng, Melissa Lyapustina, Allison Schimmel-Bristow, Jake Woodward, and Kelly Dundon for aiding in recruitment and completing participant interviews and focus groups. The authors would also like to sincerely thank Mary Shickich and Colin Drake for their help in formatting the tables and figures presented in this study. This study was supported by the Center for Diversity and Health Equity and the Clinical and Translational Research Faculty Support Fund at Seattle Children's Hospital. The funders had no involvement in study design; data collection, analysis, and interpretation; manuscript writing; or decision to submit for publication.

\section{Author Disclosure Statement}

No competing financial interests exist. This project has been presented as an oral presentation at USPATH in 2017 and as a poster presentation at the Society for Adolescent Health and Medicine Annual Meeting in March 2017.

\section{References}

1. Gridley SJ, Crouch JM, Evans Y, et al. Youth and caregiver perspectives on barriers to health care for transgender youth. J Adolesc Health. 2016;59:254-261.

2. Spack NP, Edwards-Leeper L, Feldman HA, et al. Children and adolescents with gender identity disorder referred to a pediatric medical center. Pediatrics. 2012;129:418-425.

3. Human Rights Campaign. Interactive map: clinical care programs for gender-expansive children and adolescents. www.hrc.org/resources/ interactive-map-clinical-care-programs-for-gender-nonconformingchildr Accessed March 29, 2017.

4. File T, Ryan C. Computer and internet use in the United States: 2013 American Community Survey Reports. The United States Census Bureau. www.census.gov/history/pdf/2013computeruse.pdf Accessed April 19, 2017.

5. Fox S. The social life of health information, 2011. Pew Research Center's Internet \& American Life Project. www.pewinternet.org/files/old-media/ Files/Reports/2011/PIP_Social_Life_of_Health_Info.pdf Accessed April 19, 2017.

6. Sim NZ, Kitteringham L, Spitz L, et al. Information on the World Wide Web: how useful is it for parents? J Pediatr Surg. 2007;42:305-312.

7. Chou WY, Hunt YM, Beckjord EB, et al. Social media use in the United States: implications for health communication. J Med Internet Res. 2009;11:e48.

8. Mclnroy LB, Craig SL. Transgender representation in offline and online media: LGBTQ youth perspectives. J Hum Behav Soc Environ. 2015;25:606-617.

9. Prinsloo J. Negotiating transgender identities on the internet-a South African study. Agenda: Empowering Women for Gender Equity. 2011;25:30-41.

10. Shapiro E. 'Trans'cending barriers: transgender organizing on the internet. J Gay Lesbian Soc Serv. 2004;16:165-179.
11. McDaniel BT, Coyne SM, Holmes EK. New mothers and media use: associations between blogging, social networking, and maternal well-being. Matern Child Health J. 2012;16:1509-1517.

12. Clarke JN, Lang L. Mothers whose children have ADD/ADHD discuss their children's medication use: an investigation of blogs. Soc Work Health Care. 2012;51:402-416.

13. Braun V, Clarke V. Using thematic analysis in psychology. Qual Res Psychol. 2006;3:77e101.

14. Portier K, Greer GE, Rokach L, et al. Understanding topics and sentiment in an online cancer survivor community. J Natl Cancer Inst Monogr. 2013:47:195-198.

15. Matsuda S, Aoki K, Tomizawa S, et al. Analysis of patient narratives in disease blogs on the internet: an exploratory study of social pharmacovigilance. JMIR Public Health Surveill. 2017;3:e10.

16. de Vries ALC, Doreleijers TAH, Steensma TD, Cohen-Kettenis PT. Psychiatric comorbidity in gender dysphoric adolescents. J Child Psychol Psychiatry. 2011;52:1195-1202.

17. Levine DA. Office based care for lesbian, gay, bisexual, transgender, and questioning youth. Pediatrics. 2013;132:e297-e313.

18. American Medical Association. Policy H-160.991: Health Care needs of lesbian, gay, bisexual, and transgender populations. https://searchpf .ama-assn.org/SearchML/searchDetails.action?uri=\%2FAMADoc\%2FHOD .xml-0-805.xml Accessed March 30, 2017.

19. Adelson SL; American Academy of Child and Adolescent Psychiatry (AACAP) Committee on Quality Issues (CQI). Practice parameter on gay, lesbian, or bisexual sexual orientation, gender nonconformity, and gender discordance in children and adolescents. J Am Acad Child Adolesc Psychiatry. 2012;51:957-974.

20. Daniel H, Butkus R. Lesbian, gay, bisexual, and transgender health disparities: executive summary of a policy position paper From the American College of Physicians. Ann Intern Med. 2015;163:135-137.

21. Ohlheiser A. YouTube is 'looking into' complaints that it unfairly censors LGBT videos. The Washington Post. 2017. www.washingtonpost.com/ news/the-intersect/wp/2017/03/20/youtube-is-looking-into-complaintsthat-it-unfairly-censors-lgbt-videos/?utm_term $=.9 \mathrm{~b} 7 \mathrm{c} 8953 \mathrm{a} 7 \mathrm{fd}$ Accessed March 29, 2017.

22. Vanderbilt University School of Medicine Program for LGBTI Health. LGBT Graduate Certificate Program. https://medschool.vanderbilt.edu/lgbti/ graduate-certificate Accessed March 31, 2017.

23. Horvath KJ, lantaffi A, Grey JA, Bockting W. A review of the content and format of transgender-related webpages. Health Commun. 2012;27:457466.

Cite this article as: Evans YN, Gridley SJ, Crouch J, Wang A, Moreno MA, Ahrens K, Breland DJ (2017) Understanding online resource use by transgender youth and caregivers: a qualitative study, Transgender Health 2:1, 129-139, DOI: 10.1089/trgh.2017.0011.

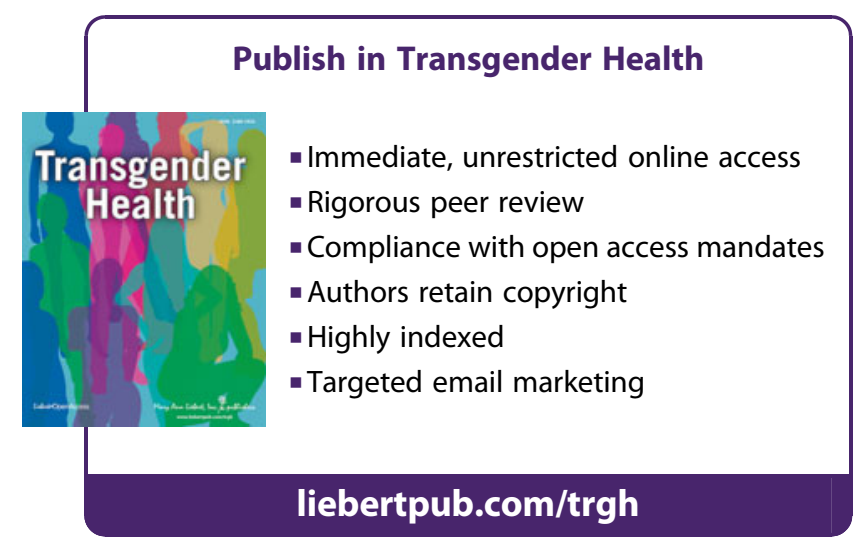

